\title{
Spinal Monoaminergic Receptors Mediate the Antinociception Produced by Glutamate in the Medullary Lateral Reticular Nucleus
}

\author{
A. J. Janss and G. F. Gebhart \\ Department of Pharmacology, College of Medicine, University of lowa, lowa City, lowa 52242
}

Focal electrical stimulation and microinjection of the excitatory amino acid glutamate in the lateral reticular nucleus (LRN) both inhibit the heat-evoked tail flick (TF) reflex in rats. The stimulation-produced inhibition from the LRN has previously been demonstrated to be mediated by spinal monoaminergic receptors. In the present study, inhibition of responses to noxious thermal stimuli by glutamate microinjected into the LRN was examined and characterized; this study is the first to examine the spinal receptors mediating inhibition produced by selective activation of cell bodies in the LRN. Microinjection of glutamate $(100 \mathrm{~mm})$ into the LRN in rats lightly anesthetized with pentobarbital produced a transient ( $<5 \mathrm{~min}$ ) inhibition of the heat-evoked TF reflex, the magnitude of which increased with the volume of glutamate injected $(100,200$, or $400 \mathrm{nl})$. This glutamate-produced inhibition of the TF reflex was antagonized by the intrathecal administration of phentolamine $(30 \mu \mathrm{g})$, yohimbine (15 and $30 \mu \mathrm{g})$, or methysergide $(15$ and $30 \mu \mathrm{g})$ to the level of the lumbar spinal cord, but was not antagonized by prazosin $(30 \mu \mathrm{g})$ or naloxone $(20 \mu \mathrm{g})$. Yohimbine (15 and 30 $\mu \mathrm{g})$ administered to the level of the cervical spinal enlargement did not significantly alter inhibition of the TF reflex produced by glutamate microinjected into the LRN.

Microinjection of glutamate (100 mM, $400 \mathrm{nl})$ into the LRN elevated TF latencies and hindpaw lick latencies in the hot plate test performed on conscious rats. This inhibition of responses to noxious thermal stimuli in conscious rats was short-lasting ( $<5 \mathrm{~min}$ ), and was also attenuated by intrathecal administration of yohimbine $(30 \mu \mathrm{g})$ or methysergide (30 $\mu \mathrm{g})$, but not by prazosin $(30 \mu \mathrm{g})$ or naloxone $(20 \mu \mathrm{g})$. While it has previously been established that cell bodies in the LRN mediate descending inhibition of spinal nociceptive reflexes, the present results establish that spinal $\alpha_{2}$-adrenoceptors and serotonin receptors mediate LRN-produced antinociception and extend our understanding of LRN-mediated modulation of nociceptive responses integrated spinally and supraspinally.

Systems that modulate spinal transmission of nociceptive information are distributed along the length of the neural axis, from the cortex (e.g., Coulter et al., 1974; Yezierski et al., 1983)

\footnotetext{
Received Dec. 1, 1986; revised Mar. 19, 1987; accepted Mar. 19, 1987.

The technical assistance of Michael Burcham and the secretarial assistance of Marilynn Kirkpatrick are gratefully acknowledged. This research was supported by Grants NS 19912, DA 02879, and T32 GM 07069.

Correspondence should be addressed to G. F. Gebhart, Department of PharInaculogy, BSB, University of Iowa, Iowa City, IA 52242.

Copyright (C) 1987 Society for Neuroscience $0270-6474 / 87 / 092862-12 \$ 02.00 / 0$
}

to the segmental level (e.g., Menétrey et al., 1977; Fitzgerald, 1982). Inhibition of reflexes or spinal dorsal horn neurons cvoked by nociceptive stimuli can be produced by focal electrical stimulation in widely distributed central loci, including the ventrobasal thalamus (Gerhart et al., 1983), hypothalamus (Carstens, 1982, 1986; Carstens et al., 1983; Cunningham et al., 1986; Aimone and Gebhart, 1987), midbrain (Reynolds, 1969; Gebhart et al., 1983a, b; Aimone and Gebhart, 1986), pons (Jones and Gebhart, 1986a, b), and medulla (Zorman et al., 1981; Hall et al., 1982; Gebhart et al., 1983a, b; Morton et al., 1983; Aimone and Gebhart, 1986; Gebhart and Ossipov, 1986). Since Reynolds first reported behaviorally defined analgesia produced by electrical stimulation in the periaqueductal gray of rats in 1969 , it has become evident that numerous supraspinal sites are involved in the centrifugal modulation of somatosensory pathways and that this may reflect the participation of multiple systems in the processing of nociceptive information. These systems differ neuroanatomically, neurochemically, and/or in the qualitative fashion in which they inhibit nociceptive transmission (e.g., Watkins and Mayer, 1982; Gebhart et al., 1983a; Gebhart, 1986). The existence of spinopetal projections from these various sources of descending inhibition makes it important to distinguish between inhibitory effects produced by activation of cell bodies and those produced by activated fibers of passage.

This is especially true for the lateral reticular nucleus (LRN), a relatively large bilateral complex of cells in the ventrolateral medulla that extends along the length of the inferior olive (Paxinos and Watson, 1982; Kalia et al., 1985a). The LRN lies at the caudal extent of the brain stem, directly in the path of descending, as well as ascending, fiber tracts (Westlund and Coulter, 1980; Jones and Yang, 1985). It is highly interconnected with structures involved in motor function (e.g., motor cortex: Brodal et al., 1967; Künzle and Wiesendanger, 1974; Corraja et al., 1977; Shokunbi et al., 1986; red nucleus: Corraja et al., 1977; Hrycyshyn and Flümerfelt, 1981; Rose, 1981; Qvist et al., 1984; Shokunbi et al., 1986; cerebellum: Corraja et al., 1977; Deitrichs and Walberg, 1979; Deitrichs, 1983; inferior olivary nucleus: Shokunbi et al. 1986; and the ventral horn of the spinal cord: Künzle, 1973; Corraja et al., 1977; Hrycyshyn and Flümerfelt, 1981; Menétrey et al., 1983, 1984), and sensory functions (e.g., sensory cortex: Brodal et al., 1967; Künzle and Wiesendanger, 1974; Corraja et al., 1977; Shokunbi et al., 1986; periaqueductal gray: Rose, 1981; Marchand and Hagino, 1983; Röste et al., 1985; nucleus raphe magnus: Qvist et al., 1983; and the dorsal horn of the spinal cord: Künzle, 1973; Corraja et al., 1977; Hrycyshyn and Flümerfelt, 1981; Menétrey et al., 1983,1984 ), which suggests that it plays a role in sensorimotor integration. 
Duggan first proposed a role for the LRN in sensory processing when he suggested that it was the source of tonic descending inhibition in the cat, since bilateral electrolytic lesions of the LRN increased the responses of dorsal horn nociceptive neurons to electrical activation of $\mathrm{C}$ fibers in the tibial nerve (Hall et al., 1982), and focal electrical stimulation in the LRN inhibited spinal neuronal responses to $\mathrm{C}$ fiber stimulation (Morton et al., 1983). Electrical stimulation in the LRN also results in inhibition of the nociceptive jaw-opening reflex in rabbits (Sotgiu, 1986) and the heat-evoked tail flick (TF) reflex in rats (Gebhart and Ossipov, 1986; Ossipov and Gebhart 1986; Janss et al., $1987 \mathrm{a}, \mathrm{b})$. Although the inhibition produced by clcctrical stimulation may be the consequence of activated descending fibers in the area of the electrode, microinjection of the excitatory amino acid glutamate, believed to selectively activate neuronal somata (Fries and Zieglgänsberger, 1974; Goodchild et al., 1982), into the LRN also inhibits the TF reflex in rats (Gebhart and Ossipov, 1986; Janss et al., 1987a, b).

Gebhart and Ossipov (1986) demonstrated that spinal $\alpha_{2}$ adrenoceptors and perhaps serotonin receptors mediate inhibition of the TF reflex produced by focal electrical stimulation in the LRN in rats lightly anesthetized with pentobarbital. It is not clear whether these spinal receptors are those mediating inhibition produced by cell bodies within the LRN or axons projecting through the area. This distinction is important since (1) there is considerable disagreement regarding the existence of spinopetal noradrenergic projections from the Al cell group adjacent to the LRN (see Discussions in Gebhart and Ossipov, 1986, and Janss et al., 1987b) and (2) descending inhibition of the TF reflex produced by stimulation in the nucleus locus coeruleus and subcoeruleus is also mediated by spinal $\alpha_{2}$-adrenoceptors (Jones and Gebhart, 1986a) and these pontine nuclei send projections to the spinal cord in the rat that course through the ventrolateral medulla in the area of the LRN (Westlund et al., 1983; Jones and Yang, 1985).

The goal of this study was to characterize the inhibition of responses to noxious thermal stimuli produced by selective activation of neurons in the LRN by microinjection of glutamate. The heat-evoked TF reflex in rats lightly anesthetized with pentobarbital was used to examine any relationship between inhibition of the nociceptive reflex and the dose/volume of glutamate microinjected; intrathecal administration of antagonists was used to identify the spinal receptors mediating the effects of glutamate microinjected into the LRN. Both the TF and hot plate (HP) tests were performed in conscious rats to examine both the antinociception produced by glutamate given in the LRN and the spinal receptors mediating the antinociception.

Portions of this work have been previously reported (Janss and Gebhart, 1986).

\section{Materials and Methods}

Surgical preparation. Male Sprague-Dawley albino rats (Biolab, St. Paul, MN) weighing $300-450 \mathrm{gm}$ on the day of surgery were used. Separate groups of animals were used to examine the effects of glutamate in the LRN on responses to noxious thermal stimuli (1) in the lightly anesthetized state and (2) 5 and $10 \mathrm{~d}$ after surgery in the conscious state. All animals were initially anesthetized with $50 \mathrm{mg} / \mathrm{kg}$ of pentobarbital sodium (Nembutal), i.p., and intrathecal (i.t.) catheters (either 7.5 or $4.5 \mathrm{~cm}$ lengths of PE10 polyethylene tubing) filled with artificial cerebrospinal fluid were inserted following the method described by Yaksh and Rudy (1976). In animals studied while only lightly anesthetized, femoral arterial and venous catheters were inserted to permit continuous monitoring of arterial blood pressure (Century CP-01 low-volume pressure transducer) and intravenous infusion of pentobarbital (see below), respectively. The rat was placed in a stereotaxic apparatus and a guide cannula (26 gauge; $0.45 \mathrm{~mm}$ O.D.) lowered to a position approximately $2 \mathrm{~mm}$ dorsal to the LRN (Paxinos and Watson, 1982). Anesthesia was maintained throughout the experiment by continuous intravenous infusion of pentobarbital $(3-6 \mathrm{mg} / \mathrm{kg} / \mathrm{hr}$ ). Body temperature (monitored rectally) was maintained between 37 and $38^{\circ} \mathrm{C}$ by a heating pad.

Rats tested while lightly anesthetized, as well as 5 and $10 \mathrm{~d}$ later, while conscious, did not have arterial or venous catheters inserted. While deeply anesthetized, a Plastic Products intracranial guide cannula (13 mm long, $0.45 \mathrm{~mm}$ O.D.; Roanoke, VA) was implanted stereotaxically, held in place with dental acrylic anchored to the skull with 3 machine screws, and closed with 30-gauge stainless steel stylets $(0.31$ $\mathrm{mm}$ O.D.). Following surgery, the rats were treated with 30,000 units of penicillin $\mathrm{G}$. These rats were tested during recovery from surgical anesthesia while lightly anesthetized to identify a site in the ventrolateral medulla where inhibition of the TF reflex could be elicited with low intensities of electrical stimulation (see the following section). Three of 12 animals undergoing this procedure were excluded from further testing because of the development of sensory or motor deficits or signs of infection. These techniques have been described in greater detail elsewhere (Yaksh and Rudy, 1976; Jensen and Yaksh, 1984; Aimone and Gebhart, 1986; Gebhart and Ossipov, 1986; Jones and Gebhart, 1986b; Ossipov and Gebhart, 1986).

Nociceptive tests. The heat-evoked TF reflex in rats lightly anesthetized with pentobarbital has been characterized (Ness and Gebhart, 1986) and used in numerous studies examining descending modulation of spinal reflexes (e.g., Zorman et al., 1981; Sandkühler and Gebhart, 1984; Aimone and Gebhart, 1986; Gebhart and Ossipov, 1986; Jones and Gebhart, 1986; Ossipov and Gebhart, 1986; Janss et al., 1987a, b). In those rats tested while only lightly anesthetized, the appropriate level of anesthesia (flexion and corneal reflexes intact) was maintained by adjusting the rate of intravenous pentobarbital infusion. The TF reflex was evoked by radiant heat applied to the ventral surface of the tail (see references above). Tail position was varied and the same position was not heated any 2 times in succession in order to prevent damage to the tail. Inhibition of the TF reflex was defined as a TF latency (the interval between exposure of the tail to, and withdrawal of the tail from, the heat source) $\geq 7 \mathrm{sec}$, when noxious heating was discontinued. The $7 \mathrm{sec}$ cutoff time (2.5-3.0 times the control TF latency) was imposed to minimize possible tissue injury (see Ness and Gebhart, 1986).

Rats tested while conscious 5 and $10 \mathrm{~d}$ following surgery were handled by the investigator daily during the surgical recovery period. On the day of testing, TF latencies were determined as described above. The control (preglutamate) TF latency was calculated for each rat as the mean of $3 \mathrm{TF}$ latencies recorded $2 \mathrm{~min}$ apart prior to the microinjection of glutamate. The HP test was performed by placing the rat on an aluminum plate maintained at $55.0 \pm 0.5^{\circ} \mathrm{C}$. The latency to a nociceptive response, identified as a lick of one of the hindpaws, was measured to the nearest $0.1 \mathrm{sec}$, and other behaviors suggesting discomfort (e.g., vigorous stomping of the hindpaws or jumping) were noted. Rats that did not respond were removed from the heated surface at $60 \mathrm{sec}$ to prevent tissue damage. A minimum of 2 min separated successive HP tests. The mean of $3 \mathrm{HP}$ latency values recorded $2 \mathrm{~min}$ apart prior to glutamate microinjection constituted the baseline (preglutamate) HP latency. The order in which HP and TF tests were administered prior to and following administration of drugs was randomized.

Intracerebral electrical stimulation. Focal electrical stimulation in all rats was used to localize sites in the ventrolateral medulla where the TF reflex could be inhibited by low intensities of electrical stimulation $(\leq 25 \mu \mathrm{A})$. Stimulating electrodes consisted of 34-gauge $(0.15 \mathrm{~mm}$ O.D.) insulated magnet wire (Belden; Richmond, IN) inserted into and extending at least $2 \mathrm{~mm}$ beyond the tip of the 26-gange guide cannula. Indifferent electrodes (anodes) were inserted subcutaneously into the lumbar region of the back. Electrical stimulation (constant cathodal current, $100 \mathrm{~Hz}, 100 \mu \mathrm{sec}$ pulses) was started $10 \mathrm{sec}$ prior to and continued during heating of the tail until the TF reflex occurred or $7 \mathrm{sec}$ had elapsed. A control TF latency in the absence of intracerebral electrical stimulation was always determined after each stimulation-produced inhibition.

In rats tested while only lightly anesthetized, stimulating electrodes were moved stepwise by lowering the guide cannula. In rats to be tested while conscious, electrodes extending progressively greater distances $(1.0-3.0 \mathrm{~mm})$ beyond the tip of the fixed Plastic Products guide cannula were inserted until a site in the caudal medulla at which the TF reflex could be inhibited with $\leq 25 \mu \mathrm{A}$ of electrical stimulation was identified. 
A.

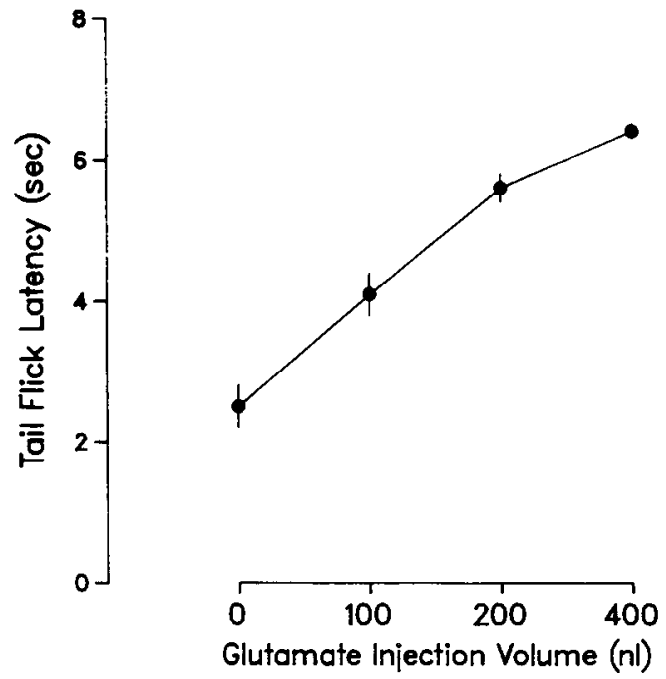

B.

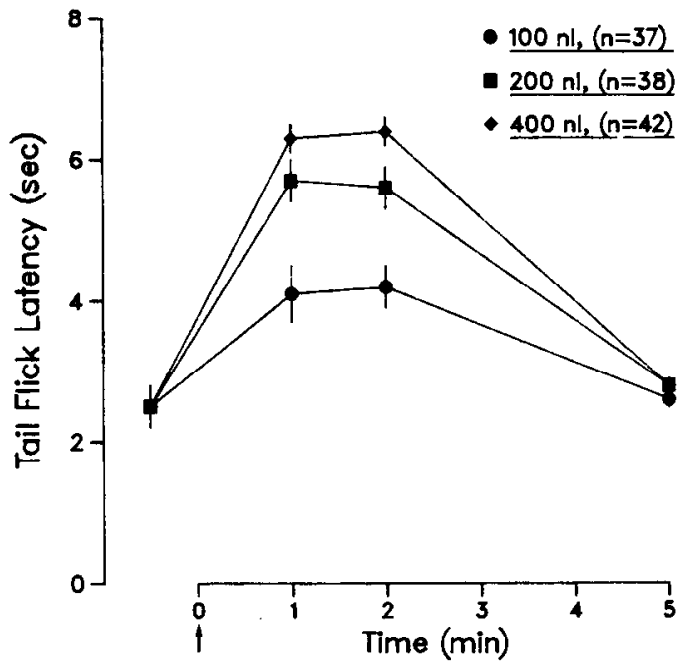

Figure 1. Inhibition of the TF reflex produced by glutamate microinjected into the LRN in rats lightly anesthetized with pentobarbital. $A$, Dose/ volume-response. TF latency (response) is plotted along the ordinate and the injection volume (dose) of glutamate (100 mm) along the abscissa. TF latency at $0 \mathrm{nl}$ connotes control (preglutamate) latency, computed as the average of 3 TF trials recorded 2 min apart prior to microinjection of glutamate. The TF latency recorded at 1 and 2 min following administration of glutamate did not differ significantly at any volume (see $B$ ), so the average of the 2 latencies was used to compute the points in $A$. Values are presented as means \pm SEM. The number of subjects for each point is indicated in $B$. Injection sites for the data presented above are depicted in Figures $2 B, 3 B$, and $4 B$. The TF latency values at 100,200 , and $400 \mathrm{nl}$ arc significantly different $(p \leq 0.05)$ from the control (preglutamate) TF latency (repeated-measures ANOVA and Tukey's studentized range test for post hoc comparison). $B$, Time course. TF latency is plotted against time following microinjection of 100,200 , or $400 \mathrm{nl}$ of glutamate into the LRN at time 0 (upward-pointing arrow). Injection sites are illustrated in Figures $2 B, 3 B$, and $4 B$. TF latency prior to time 0 represents the control (preglutamate) TF latency, or average of 3 trials prior to the administration of glutamate. Values are presented as means \pm SEM. The TF latency values at 1 and $2 \mathrm{~min}$ in all 3 curves differ significantly $(p \leq 0.05)$ from the control (preglutamate) TF latency (repeated-measures ANOVA).

Intracerebral and intrathecal drug administration. Stimulating electrodes were replaced with microinjection cannulas ( 33 gauge; $0.20 \mathrm{~mm}$ O.D.) after identification of an inhibitory site in the ventrolateral medulla in those animals in which the effects of glutamate on the TF reflex where examined while lightly anesthetized. Monosodium glutamate (100 $\mathrm{mm}$ aqueous solution, pH 6.8; Sigma) was microinjected in 100,200 , or $400 \mathrm{nl}$ volumes over a period of $1 \mathrm{~min}$, and TF latencics detcrmincd at 1,2 , and $5 \mathrm{~min}$. The different volumes of glutamate were injected in rats in random order, with a minimum of 10 min separating microinjections.

Pharmacological receptor antagonists dissolved in normal saline were delivered intrathecally in volumes of 7.5 or $15 \mu \mathrm{l}$ and the intrathecal cannula cleared of drug with a $7.5 \mu \mathrm{l}$ injection of the vehicle. The antagonists included naloxone $\mathrm{HCl}(20 \mu \mathrm{g}$; Dupont); phentolamine (30 $\mu \mathrm{g}$; Sigma); yohimbine $\mathrm{HCl}$ (15 and $30 \mu \mathrm{g}$; Sigma); methysergide maleate

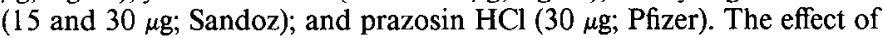
injection volume on nociceptive thresholds was tested by the injection of $20 \mu \mathrm{l}$ of normal saline, i.t., the vehicle for the antagonists administered, excepting prazosin, which was delivered in aqueous solution because of its lower solubility. TF latencies were determined at $2 \mathrm{~min}$ intervals beginning $4 \mathrm{~min}$ after intrathecal drug administration, and baseline TF latency was computed as the average of these latencies. Glutamate microinjections $(100,200$, and $400 \mathrm{nl})$ were repeated $10 \mathrm{~min}$ after the intrathecal injection. Following any changes in the efficacy of intracranially administered glutamate in inhibiting the TF reflex, the effects of the antagonists were allowed to dissipate (40-60 $\mathrm{min}$ ), whereupon glutamate was readministered into the LRN to confirm recovery of its inhibitory efficacy.

Baseline TF and HP latencies were determined (mean of 3 trials of each test prior to administration of glutamate) 5 and $10 \mathrm{~d}$ after surgery in conscious rats. A 33-gauge microinjection cannula was lowered to the position where electrical stimulation had previously produced inhibition of the TF reflex (see preceding section). Two injections of glutamate, separated by a 15 min interval, were made prior to and following the intrathecal administration of antagonist. Glutamate (100 mM, 400 $\mathrm{nl}$ ) was injected over a $1 \mathrm{~min}$ period. Either TF tests (latency monitored at 1, 2, 5, and $10 \mathrm{~min}$ ) or HP tests (latency monitored at 1,3, 5, and
$10 \mathrm{~min}$ ) were performed following the first microinjection of glutamate, and the alternate nociceptive test was performed after the second glutamate microinjection. Thus, each rat underwent $4 \mathrm{TF}$ and $4 \mathrm{HP}$ trials prior to intrathecal administration of a receptor antagonist. This protocol was repeated $10 \mathrm{~min}$ after intrathecal treatment with an antagonist. The order of testing (HP versus TF test) following glutamate in the LRN was varied between subjects. A group of rats received $400 \mathrm{nl}$ of distilled water (the vehicle) intracranially into a site where glutamate had previously elevated response latencies, and HP and TF tests were readministered to determine whether the inhibitory effect was drug-specific or secondary to microinjection of the vehicle.

Pharmacological receptor antagonists (yohimbine $\mathrm{HCl}, 30 \mu \mathrm{g}$; prazosin $\mathrm{HCl}, 30 \mu \mathrm{g}$; methysergide maleate, $30 \mu \mathrm{g}$; and naloxone $\mathrm{HCl}, 20$ $\mu \mathrm{g}$ ) were injected intrathecally in $15 \mu \mathrm{l}$ of vehicle, followed by a $7.5 \mu \mathrm{l}$ injection of the vehicle. Two minutes following administration of an antagonist, control response latencies (preglutamate) were determined by calculating the mean of 3 trials per nociceptive test, each trial separated by $2 \mathrm{~min}$. Glutamate microinjections into the LRN and nociceptive tests were then repeated as described in the preceding paragraph and recovery of the efficacy of glutamate was demonstrated when appropriate.

Histology. Animals were killed with an overdose of pentobarbital and injection/stimulation sites marked with an electrolytic lesion $(500 \mu \mathrm{A}$ DC anodal current, $3 \mathrm{sec}$ ). The brains were removed and fixed in $10 \%$ formalin for subsequent histological examination. Fast green dye (7.5 or $15 \mu \mathrm{l}$ of a saturated solution) was injected intrathecally, followed by a $7.5 \mu \mathrm{l}$ injection of saline. Catheter placement and the extent of diffiusion of injected dye were monitored upon extraction of the spinal cord by hydraulic pressure.

Analysis of data. Statistical analyses of the data (i.e., TF and HP latencies and blood pressure before and after glutamate microinjection) were made using Student's $t$ test for grouped or paired data, a 1-way ANOVA, or a repeated-measures ANOVA (SAS computer-assisted program) with Tukey's studentized range test for post hoc comparisons; $p \leq 0.05$ was considered significant. Differences in TF and HP latencies before and after intrathecal treatment were analyzed within the various treatment groups, such that each animal served as its own control. No 
A.

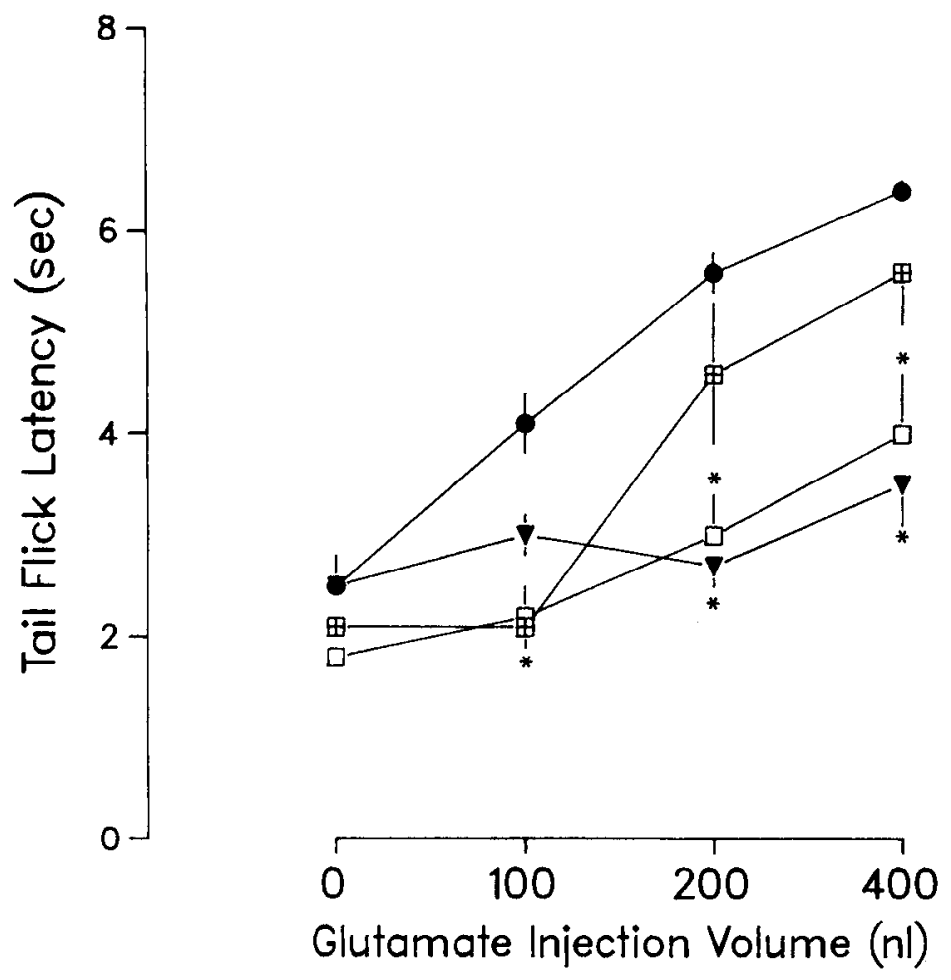

B.

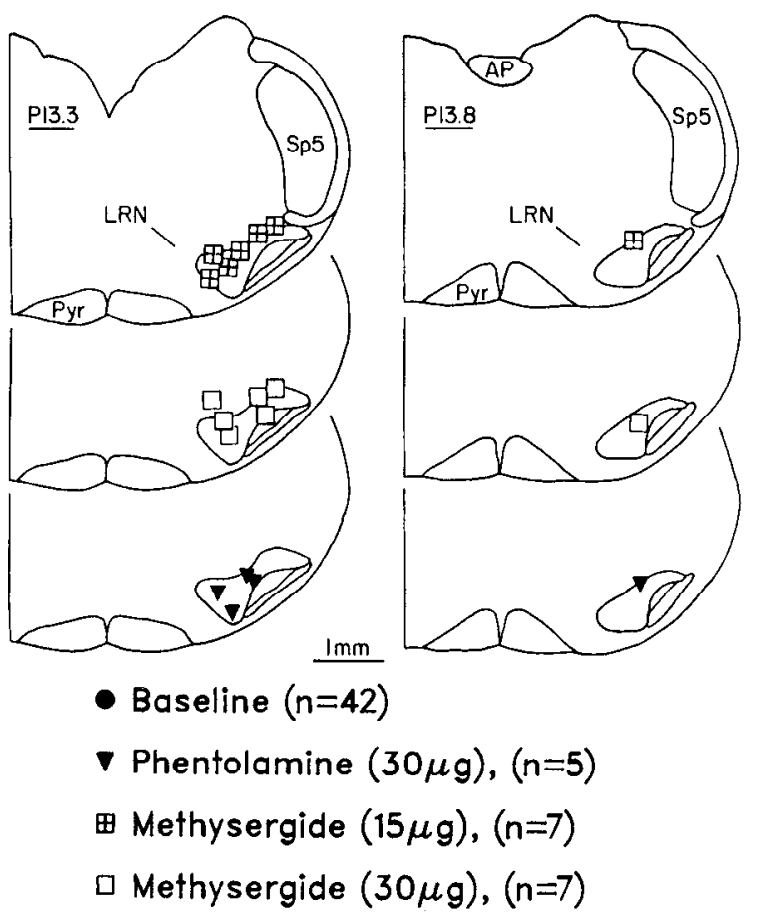

Figure 2. A, Effcct of intrathecal administration of phentolamine or methysergide on inhibition of the TF reflex produced by glutamate (100 mm) microinjected into the LRN of rats lightly anesthetized with pentobarbital. The dose/volume-response allows comparison of the inhibition of the TF reflex by glutamate in the LRN in the absence (baseline; this curve is also depicted in Fig. $1 \mathrm{~A}$ ) and the presence of phentolamine or methysergide $(15$ and $30 \mu \mathrm{g})$ delivered intrathecally to the level of the lumbar enlargement. TF latency at $0 \mathrm{nl}$ represents the average of $3 \mathrm{TF}$ trials recorded prior to microinjection of glutamate into the LRN, but after intrathecal treatment. The points on the graph are the average TF latencies recorded 1 and 2 min after microinjection of glutamate. Values are presented as means \pm SEM. * Significantly different $(p \leq 0.05)$ from corresponding baseline TF latency (repeated-measures ANOVA and Tukey's studentized range test for post hoc comparison). $B$, Microinjection sites for glutamate in the ventrolateral medulla in rats treated with intrathecal phentolamine or methysergide, as indicated to the left.

significant differences in control (preglutamate) TF and HP latencies and postglutamate/preintrathecal antagonist TF and HP latencies were found between groups treated with different receptor antagonists, so the data were pooled; pooled data represent the effect of glutamate microinjected into the LRN in the absence of intrathecal drug or vehicle and are presented as the baseline values (see Tables 1 and 2, Figs. 15).

\section{Results}

Descending inhibition in lightly anesthetized rats

Microinjection of the excitatory amino acid glutamate into the ventrolateral medulla produced a significant, but transient $(<5$ min), elevation in TF latency in rats lightly anesthetized with pentobarbital (Fig. 1). Injection sites, illustrated in Figures $2 B$, $3 B$, and $4 B$, were all in or near the LRN. TF latencies recorded 1 and $2 \mathrm{~min}$ following the microinjection of glutamate did not differ significantly at any volume of injection (see Fig. $1 B$ ), so that all statistical comparisons were performed on the average of the 2 latencies. Inhibition of the heat-evoked TF reflex was progressivcly grcatcr with larger injection volumes of glutamate (Fig. 1, Table 1). Glutamate injected in 100, 200, or $400 \mathrm{nl}$ volumes into the LRN produced significant increases $-64 \pm$ $12 \%(n=37), 124 \pm 12 \%(n=38)$, and $156 \pm 8 \%(n=42)$, respectively - in TF latencies from the baseline latency $(2.5 \pm$ $0.1 \mathrm{sec})$. The volume of glutamate microinjected into the LRN that was required to produce a 2 -fold elevation in the TF latency, as computed from a linear regression through the data points in Figure $1 A$, was $160 \mathrm{nl}(16 \mathrm{nmol})$.

Glutamate microinjected into the LRN also produced a cardiovascular depressor response (means, $15.3 \pm 2.4,20.2 \pm 6.0$, and $23.1 \pm 1.9 \mathrm{~mm} \mathrm{Hg}$ decreases in diastolic blood pressure for 100,200 , or $400 \mathrm{nl}$ injections of glutamate, respectively). This depressor effect exhibited dependence on dose/volume, since the reductions in diastolic blood pressure produced by 100 and $400 \mathrm{nl}$ of glutamate were significantly different. However, the decreases in blood pressure did not correlate with elevations in the TF latency when analyzed with Spearman's rank-correlation test: $r_{s}=-0.02,0.06$, and -0.05 for 100,200 , and 400 $\mathrm{nl}$ injection volumes of glutamate, respectively.

Both the nonselective adrenoceptor antagonist phentolamine $(30 \mu \mathrm{g} ; n=5)$ and the serotonin receptor antagonist methysergide $(30 \mu \mathrm{g} ; n=7)$, when administered to the level of the lumbar spinal cord, significantly attenuated inhibition of the TF reflex produced by glutamate $(100,200$, or $400 \mathrm{nl})$ microinjected into the LRN of lightly anesthetized rats (Fig. 2, Table 1). A lesser dose of methysergide $(15 \mu \mathrm{g} ; n=7)$ significantly reduced only the effect of the $100 \mathrm{nl}$ microinjection of glutamate on the TF reflex, suggesting that the antagonism by methysergide is dependent upon dose. Both doses of methysergide reduced the control (preglutamate) TF latencies from the baseline value, although the reductions were not statistically significant (see Fig. 2, Table 1). 
Table 1. Effect of receptor antagonists administered intrathecally on inhibition of the TF reflex by microinjection of glutamate into the LRN in lightly anesthetized rats

\begin{tabular}{|c|c|c|c|c|c|c|}
\hline & & & Tail flick later & $(\mathrm{sec} \pm \mathrm{SEM})$ & & \\
\hline & & & & Postglutama & (nl) & \\
\hline Intrathecal treat & ent & $n$ & Preglutamate & 100 & 200 & 400 \\
\hline None (baseline) & & 42 & $2.5 \pm 0.1$ & $4.1 \pm 0.3$ & $5.6 \pm 0.2$ & $6.4 \pm 0.1$ \\
\hline Vehicle & $20 \mu \mathrm{l}$ & 7 & $2.6 \pm 0.1$ & $3.3 \pm 0.7$ & $6.0 \pm 1.0$ & $6.0 \pm 0.5$ \\
\hline Phentolamine & $30 \mu \mathrm{g}$ & 5 & $2.5 \pm 0.2$ & $3.0 \pm 0.2$ & $2.7 \pm 0.2^{a}$ & $3.4 \pm 0.4^{a}$ \\
\hline Methysergide & $15 \mu \mathrm{g}$ & 7 & $2.1 \pm 0.2$ & $2.1 \pm 0.3^{a}$ & $4.6 \pm 0.7$ & $5.6 \pm 0.7$ \\
\hline & $30 \mu \mathrm{g}$ & 7 & $1.8 \pm 0.1$ & $2.2 \pm 0.3$ & $3.0 \pm 0.4^{a}$ & $4.0 \pm 0.6^{a}$ \\
\hline Yohimbine & $15 \mu \mathrm{g}$ & 11 & $2.0 \pm 0.1$ & $2.0 \pm 0.1^{a}$ & $3.3 \pm 0.9^{a}$ & $5.3 \pm 0.6$ \\
\hline & $30 \mu \mathrm{g}$ & 9 & $1.8 \pm 0.1^{a}$ & $1.8 \pm 0.4^{a}$ & $2.0 \pm 0.3^{a}$ & $1.8 \pm 0.2^{a}$ \\
\hline Yohimbine & $15 \mu \mathrm{g}$ & 6 & $2.4 \pm 0.2$ & $4.8 \pm 0.6$ & $5.9 \pm 0.2$ & $6.5 \pm 0.3$ \\
\hline (cervical) & $30 \mu \mathrm{g}$ & 6 & $2.4 \pm 0.1$ & $3.0 \pm 0.6$ & $3.7 \pm 0.8$ & $4.8 \pm 0.7$ \\
\hline Prazosin & $30 \mu \mathrm{g}$ & 9 & $2.3 \pm 0.2$ & $5.4 \pm 0.8$ & $5.9 \pm 0.5$ & $6.4 \pm 0.3$ \\
\hline Naloxone & $20 \mu \mathrm{g}$ & 8 & $2.4 \pm 0.1$ & $3.4 \pm 0.7$ & $5.4 \pm 0.3$ & $6.2 \pm 0.4$ \\
\hline
\end{tabular}

TF latencies represent the mean of 3 values recorded $2 \mathrm{~min}$ apart prior to microinjection of glutamate (preglutamate), or recorded 1 and 2 min following microinjection of glutamate into the LRN (postglutamate). Glutamate injection sites are illustrated in Figures $2 B, 3 B$, and $4 B$. Baseline values indicate TF latencies in the absence of any intrathecal treatment. Antagonists or vehicle (normal saline) were administered to the level of the lumbar enlargement (catheter, $7.5 \mathrm{~cm}$ ), with the exception of a group (cervical) in which yohimbine was administered to the level of the cervical spinal enlargement (catheter, $4.5 \mathrm{~cm}$ ).

" Significantly different $(p \leq 0.05$ ) from corresponding baseline TF latency (2-way ANOVA and Tukcy's studentized range test for post hoc comparison).

Resolution of the spinal adrenoceptors mediating inhibition of the TF reflex by glutamate was achieved by the intrathecal administration of the selective $\alpha_{1}$-adrenoceptor antagonist prazosin or the $\alpha_{2}$-adrenoceptor antagonist yohimbine (Fig. 3, Table 1). Prazosin ( $30 \mu \mathrm{g} ; n=7)$ did not alter the descending inhibition produced by glutamate, whereas yohimbine $(30 \mu \mathrm{g} ; n=9)$ significantly decreased the baseline TF latency and completely blocked the inhibitory effects of 100,200, and $400 \mathrm{nl}$ microinjections of glutamate into the LRN. Yohimbine administered in a lesser, $15 \mu \mathrm{g}$ dose $(n=11)$ shifted the dose/volume-response curve to the right, significantly reducing the inhibition of the TF reflex produced by 100 and $200 \mathrm{nl}$ microinjections of glutamate. Thus, spinal $\alpha_{2}$-adrenoceptors, as well as spinal serotonin receptors, appear to be involved in the inhibition of the $T F$ reflex produced by chemical activation of cell bodies in the LRN, a result consistent with the stimulation-produced inhibition of the TF reflex from the LRN (Gebhart and Ossipov, 1986).

Intrathecal administration of naloxone ( $20 \mu \mathrm{g} ; n=8)$ did not alter inhibition of the TF reflex by glutamate microinjected into the LRN in rats lightly anesthetized with pentobarbital (Fig. 4, Table 1). Normal saline ( $20 \mu \mathrm{l} ; n=7)$ was injected intrathecally to control for effects of the vehicle; Figure 4 also illustrates the lack of effect of the saline injection on either baseline TF latency or inhibition of the TF reflex produced by glutamate.

An additional control experiment was performed to determine the extent to which rostrad diffusion of an intrathecally administered receptor antagonist might contribute to the attenuation of inhibition of the TF reflex produced by glutamate. Yohimbine injected into the intrathecal space at the level of the cervical spinal cord $(4.5 \mathrm{~cm}$ i.t. catheter) in $30(n=6)$ and 15 $\mu \mathrm{g}(n-6)$ doses did not significantly affect elevation of TF latencies following microinjection of 100,200 , or $400 \mathrm{nl}$ of glutamate into the LRN (Table 1). Dye injections made to verify catheter placement after administration of a lethal dose of pentobarbital confirmed the extent of diffusion of the injected vol- umes. Both 7.5 and $15 \mu$ injections of Fast green dye administered to the level of the lumbar spinal cord $(7.5 \mathrm{~cm}$ catheter) stained only the lumbar spinal tissue. Injection of dye to the level of the cervical spinal cord in the same volumes stained the cerebellum, brain stem, and the cervical spinal cord. Yohimbine administered in these shorter intrathecal catheters did not significantly alter the inhibitory effects of glutamate microinjected into the LRN, suggesting that supraspinal $\alpha_{2}$-adrenoceptors do not play a role in the inhibition of the TF reflex produced by activation of cell bodies in the LRN. The smaller volume of dye $(7.5 \mu \mathrm{l})$ administered to the level of the cervical spinal cord ( $4.5 \mathrm{~cm}$ catheters) was limited to the cervical spinal cord $(n=4)$; however, $15 \mu$ l of dye administered to the level of the cervical spinal cord did result in light staining of the lumbar spinal tissue in 3 of 4 animals. The modest, insignificant attenuation in the efficacy of glutamate by the $30 \mu \mathrm{g}$ dose of yohimbine delivered to the cervical spinal cord was likely the result of diffusion of the antagonist to the lumbar spinal cord, since similar intrathecal injections of an equal volume of dye lightly stained the surface of the lumbar spinal cord.

\section{Antinociception in conscious rats}

Microinjection of glutamate into the LRN also inhibited the responses to noxious thermal stimuli in conscious rats with a time course similar to that of the inhibition of the TF reflex in lightly anesthetized rats. Glutamate $(100 \mathrm{~mm}, 400 \mathrm{nl})$ microinjected into the LRN produced a short-lasting ( $\leq 5 \mathrm{~min}$ ) but significant increase in both TF and HP latencies (Fig. 5, Table 2 ). The average of the TF latencies recorded 1 and $2 \mathrm{~min}$ after glutamate microinjection ( $400 \mathrm{nl}$ ) was significantly elevated $(108 \pm 12 \% ; n=9)$ from the baseline TF latency $(2.6 \pm 0.2$ $\mathrm{sec})$. Average HP latencies recorded at the 1 and $3 \mathrm{~min}$ test intervals were elevated significantly $(376.0 \pm 33.0 \% ; n=8)$ from the baseline HP latency $(9.8 \pm 1.0 \mathrm{sec})$. Thus, glutamate microinjected into the LRN in awake rats produced greater than 2- and 4-fold increases in TF and HP latencies, respectively. 


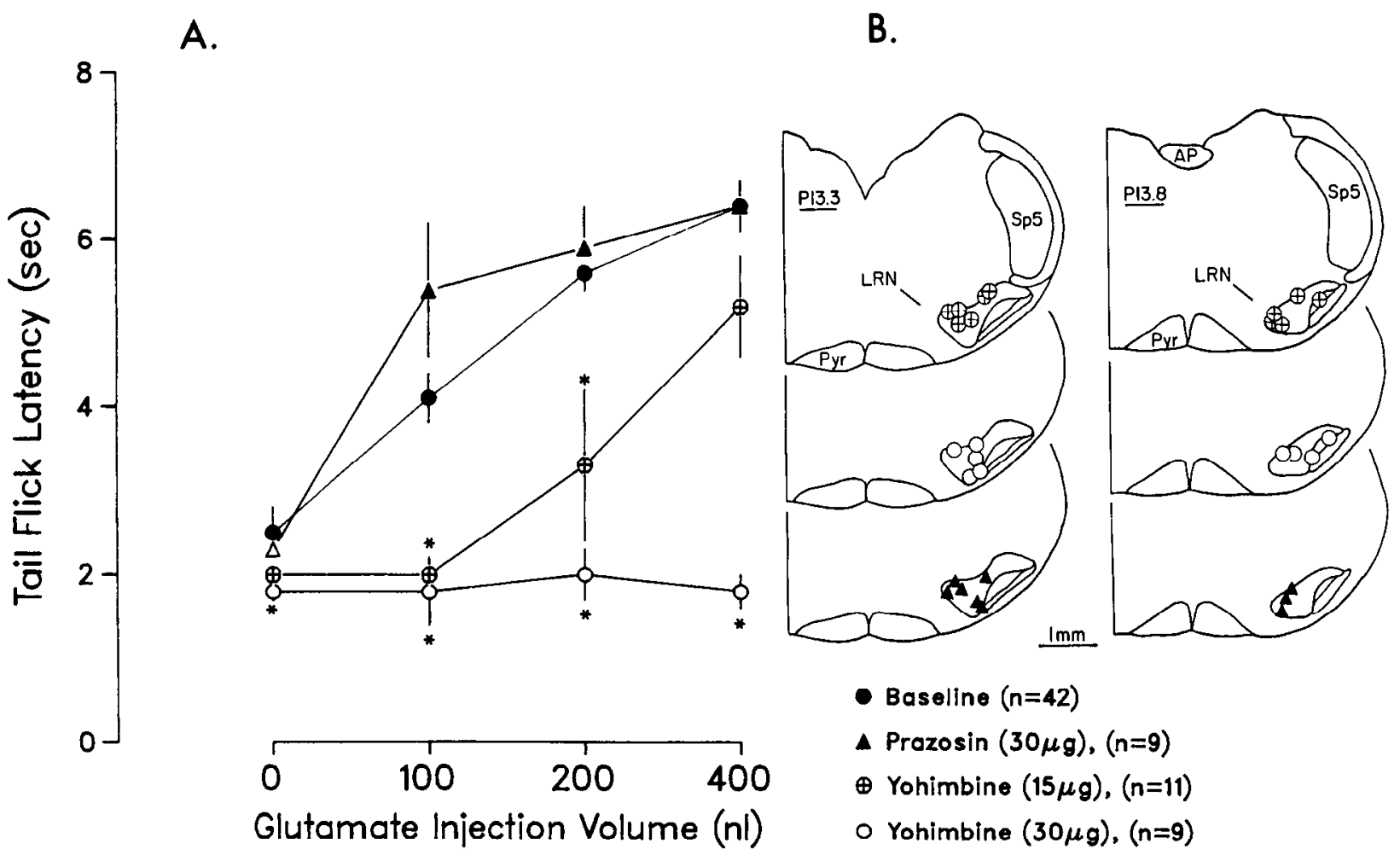

Figure 3. A, Effect of intrathecal administration of prazosin or yohimbine on inhibition of the TF reflex produced by glutamate (100 mM) microinjected into the LRN of rats lightly anesthetized with pentobarbital. The dose/volume-response illustrates how the selective $\alpha_{2}$-adrenoceptor antagonist yohimbine ( 15 and $30 \mu \mathrm{g} ; n=9$ ) attenuated inhibition of the TF reflex produced by glutamate (baseline; this curve is also illustrated in Fig. 1A). The selective $\alpha_{1}$-adrenoceptor antagonist prazosin did not affect glutamate-produced inhibition of the TF reflex. The TF latency at $0 \mathrm{nl}$ represents the avcrage of $3 \mathrm{TF}$ trials recorded prior to microinjection of glutamate into the LRN, but after intrathecal treatment. The points on the graph are the average TF latencies recorded 1 and $2 \mathrm{~min}$ after microinjection of glutamate. Values are presented as means \pm SEM. * Significantly different $(p \leq 0.05)$ from corresponding baseline (repeated-measures ANOVA with Tukey's studentized range test for post hoc comparisons). $B$, Glutamate microinjection sites in the ventrolateral medulla in rats in which yohimbine or prazosin was administered intrathecally, as indicated to the left.

Injection sites in this group of animals, depicted in Figure 5, are all in or adjacent to the LRN.

Although the hindpaw lick was clearly inhibited in the HP test by glutamate microinjected into the LRN, rats placed on the $55^{\circ}$ heated surface appeared to be agitated (stomping of foreand hindpaws) and often attempted to escape. This sharply contrasts with the antinociception produced by analgesic agents such as morphine, which are associated with an apparent indifference to the noxious thermal stimulation of the hot plate (Yaksh and Rudy, 1978).

Statistical analysis revealed no significant differences in test latencies that could be ascribed to the order of administration of the TF or HP tests, or to the time of testing following surgical preparation ( 5 or $10 \mathrm{~d}$ ). Microinjection of $400 \mathrm{nl}$ of water (vehicle) into sites where glutamate had previously produced a significant elevation of TF and HP latencies (Fig. 5, Table 2) did not produce any significant change in response latencies from baseline values, which strengthens the view that the inhibition of the TF reflex and HP hindpaw lick that occurs following microinjection of glutamate into the LRN is not the effect of the vehicle or of any mechanical disruption produced by the injection volume.

Microinjection of glutamate into the I RN in conscious rats also produced motor rigidity, irregular respiration, and vocalization lasting $30-45 \mathrm{sec}$, which reliably dissipated prior to nociceptive testing at the $1 \mathrm{~min}$ interval. Similar effects following the microinjection of glutamate into the ventromedial medulla or periaqueductal gray (Jensen and Yaksh, 1984), or of various pharmacological agonists into the LRN (Ossipov and Gebhart, 1986), have been reported. Although rigidity, breathing patterns, and vocalization were not systematically evaluated in this study, they appeared to be related to activation of cell bodies, as they were not produced by microinjection of $400 \mathrm{nl}$ of water in any of the 5 animals receiving this treatment.

Intrathecal administration of monoaminergic or opioid receptor antagonists to the level of the lumbar enlargement prior to glutamate microinjection into the LRN of awake, behaving rats confirmed the findings from similar injections made in rats lightly anesthetized with pentobarbital (Fig. 5, Table 2). Methysergide $(30 \mu \mathrm{g})$ and yohimbine $(30 \mu \mathrm{g})$ both antagonized the inhibition of the TF reflex and HP responsc produced by glutamate. Yohimbine also significantly shortened baseline TF and HP latencies. Neither prazosin $(30 \mu \mathrm{g})$ nor naloxone $(20 \mu \mathrm{g})$ had any significant effect on baseline TF or HP latencies or on inhibition of these responses by glutamate.

None of the pharmacological antagonists administered intrathecally to conscious rats eliminated the animals' previously described rigidity or altered their breathing patlerns following intra-LRN injection of glutamate.

\section{Discussion}

Descending inhibition from the ventrolateral medulla has been studied previously and is confirmed here. The present report 
A.

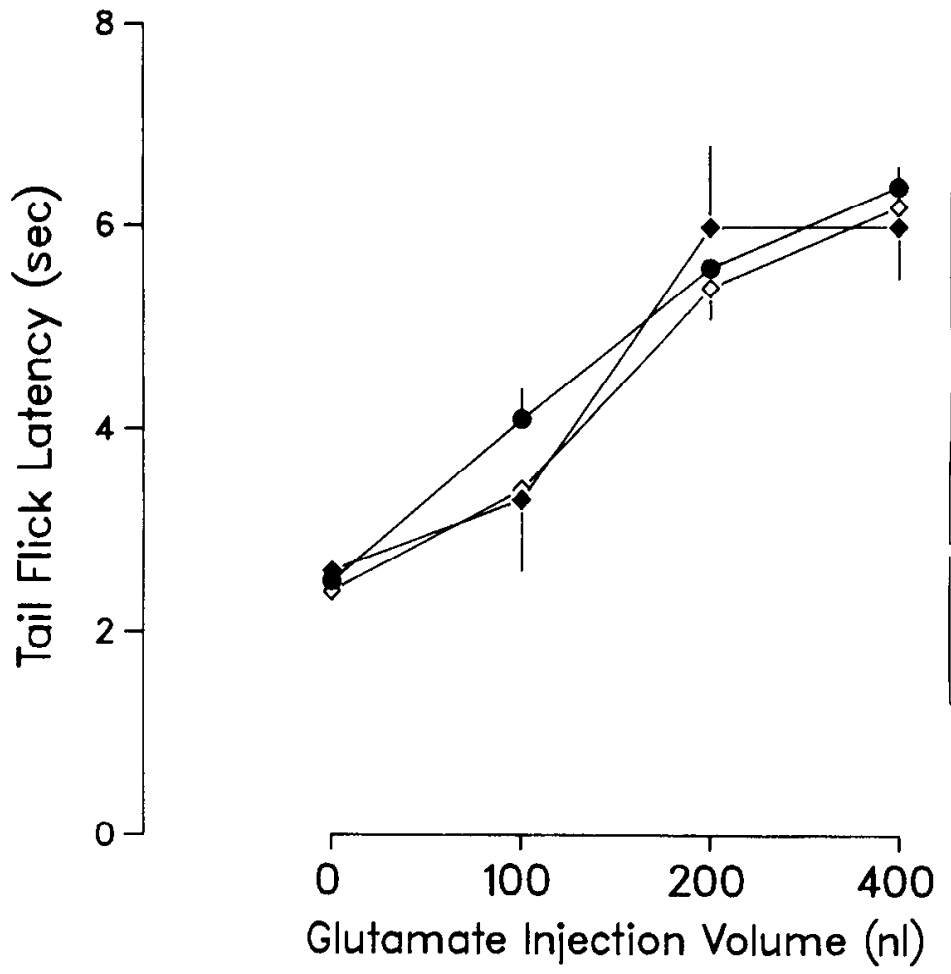

B.
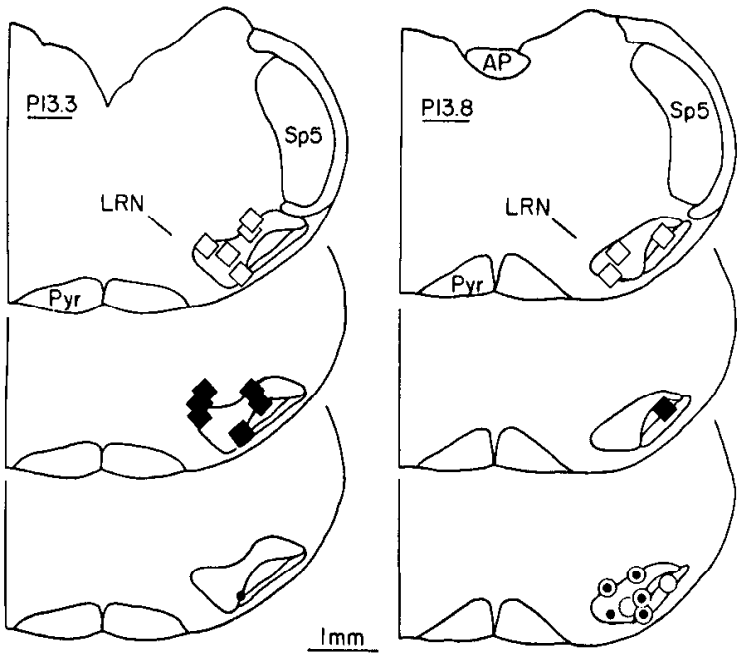

- Baseline $(n=42)$

- Saline $(20 \mu 1),(n=7)$

$\diamond$ Naloxone $(20 \mu \mathrm{g}),(\mathrm{n}=8)$

Figure 4. A, Effect of intrathecal administration of naloxone or saline on inhibition of the TF reflex produced by glutamate (100 mM) microinjected into the LRN of rats lightly anesthetized with pentobarbital. The dose/volume-response illustrates the lack of effect of naloxone or normal saline delivered intrathecally to the level of the lumbar enlargement upon inhibition of the TF reflex produced by glutamate in the LRN (baseline; this curve is also depicted in Fig. $1 A$ ). The TF latency at $0 \mathrm{nl}$ represents the average of $3 \mathrm{TF}$ trials recorded prior to microinjection of glutamate into the LRN, but after intrathecal treatment. The points on the graph are the average of TF latencies recorded 1 and 2 min after microinjection of glutamate. Values are presented as means \pm SEM. $B$. Glutamate microinjection sites in the ventrolateral medulla in rats in which naloxone or normal saline was administered intrathecally. Also depicted are the microinjection sites of rats with intrathecal catheters extending to the cervical enlargement $(4.5 \mathrm{~cm})$ and treated with either $15(0)$ or $30(0) \mu \mathrm{g}$ of yohimbine, i.t. (see text).

focused on antinociception from the ventrolateral medulla mediated by cell bodies in the LRN, as opposed to inhibition produced by focal electrical stimulation that activates both cell bodies and fibers of passage. The results (1) confirm that selective activation of cell bodies in the LRN mediates inhibition of the spinally mediated TF reflex in lightly anesthetized rats (Gebhart and Ossipov, 1986; Janss et al., 1987a, b), (2) establish that cell bodies in the LRN also mediate inhibition of spinal reflexes and responses to noxious thermal stimuli organized supraspinally in conscious rats, and (3) demonstrate that the inhibitory effects from the somata in the LRN that are listed above are mediated by spinal $\alpha_{2}$-adrenoceptors and serotonin receptors.

The inhibitory effects of glutamate microinjected into the LRN were short-lived, increasing with the injection volume. Similar brief time courses for the inhibition of responses to noxious stimuli produced by microinjection of glutamate into the LRN (Gebhart and Ossipov, 1986), as well as into other supraspinal sites (Satoh et al., 1983; Jensen and Yaksh, 1984; Jones and Gebhart, 1986a, b), have been reported. The doses of glutamate microinjected into the LRN (10-40 nmol) that significantly elevated TF and HP latencies in the present report are less than or comparable to those reported to produce inhibition of responses to noxious stimuli when microinjected into various supraspinal sites in the rat. The dose of glutamate that elevated the TF latency 2 -fold from baseline when microinjected into the LRN was calculated to be $16 \mathrm{nmol}$. Satoh et al. (1983) reported that the antinociceptive effects of glutamate microinjected into the nucleus raphe magnus and the nucleus reticularis paragigantocellularis in rats exhibited dose-dependence; their computed effective-dose $e_{50} s$ for inhibition of the tail-pinch response were 82.5 and $23.0 \mathrm{nmol}$ of glutamate in the nucleus raphe magnus and nucleus reticularis paragigantocellularis, respectively. Jensen and Yaksh (1984) observed elevation of both TF and HP latencies after injection of $30 \mathrm{nmol}$ of glutamate into the periaqueductal gray or the ventral medial medulla in conscious rats, and inhibition of flexion reflexes in lightly anesthetized rats have been reported following microinjection of 25 $50 \mathrm{nmol}$ of glutamate into the nucleus raphe magnus (Behbehani and Fields, 1979) and of $50 \mathrm{nmol}$ of glutamate into the locus coeruleus (Jones and Gebhart, 1986a, b).

Intrathecal administration of various pharmacological receptor antagonists to either lightly anesthetized or conscious rats implicates spinal $\alpha_{2}$-adrenoceptors and serotonin receptors in the inhibition of nociceptive responses from the LRN. Phentolamine, a nonselective $\alpha$-adrenoceptor antagonist, and yohimbine, a selective $\alpha_{2}$-adrenoceptor antagonist, but not the $\alpha_{1}$ adrenoceptor antagonist prazosin, attenuated significantly the antinociceptive efficacy of glutamate microinjected into the LRN (see Starke, 1981, for a review of $\alpha$-adrenoceptor antagonists). Similar results have been reported by Gebhart and Ossipov (1986) in studies of spinal receptors mediating inhibition of the TF reflex produced by focal electrical stimulation in the LRN. 
A. Tail Flick

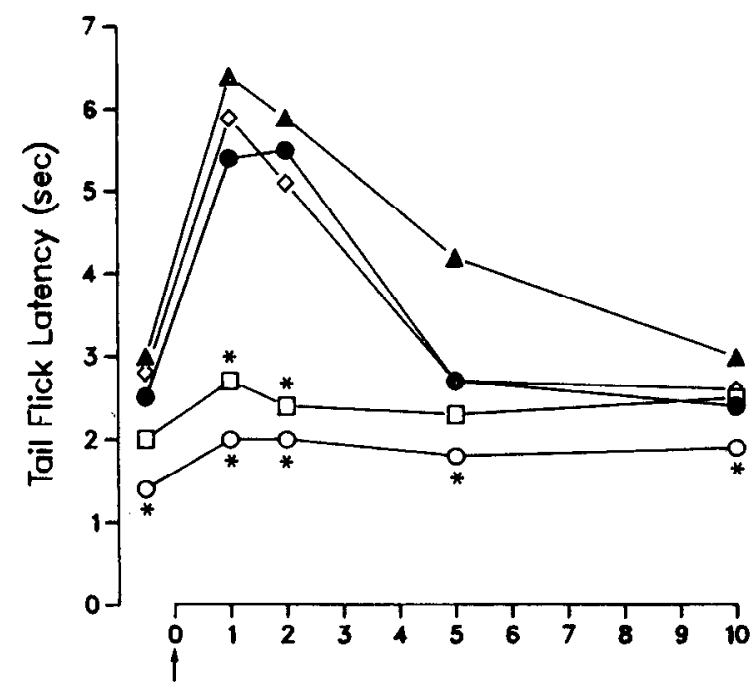

B. Hot Plate

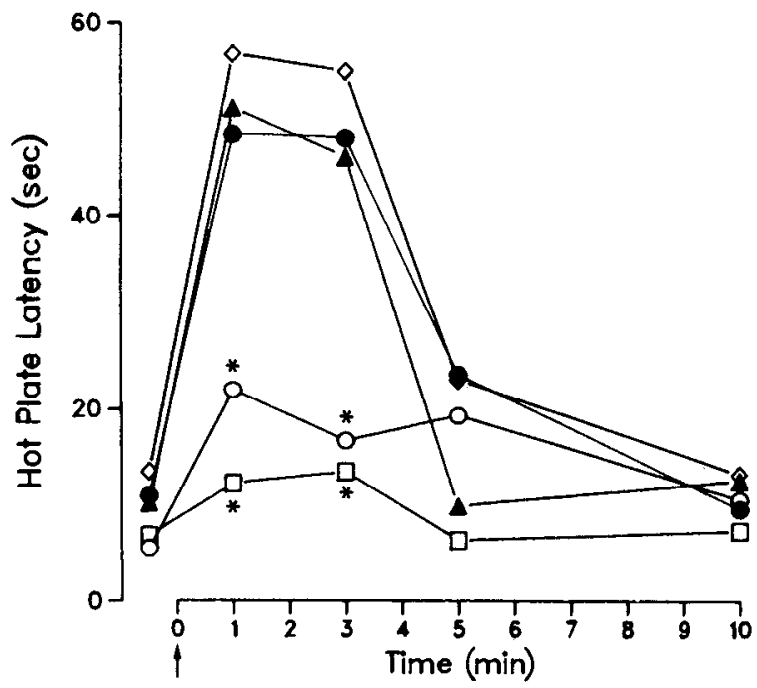

C.
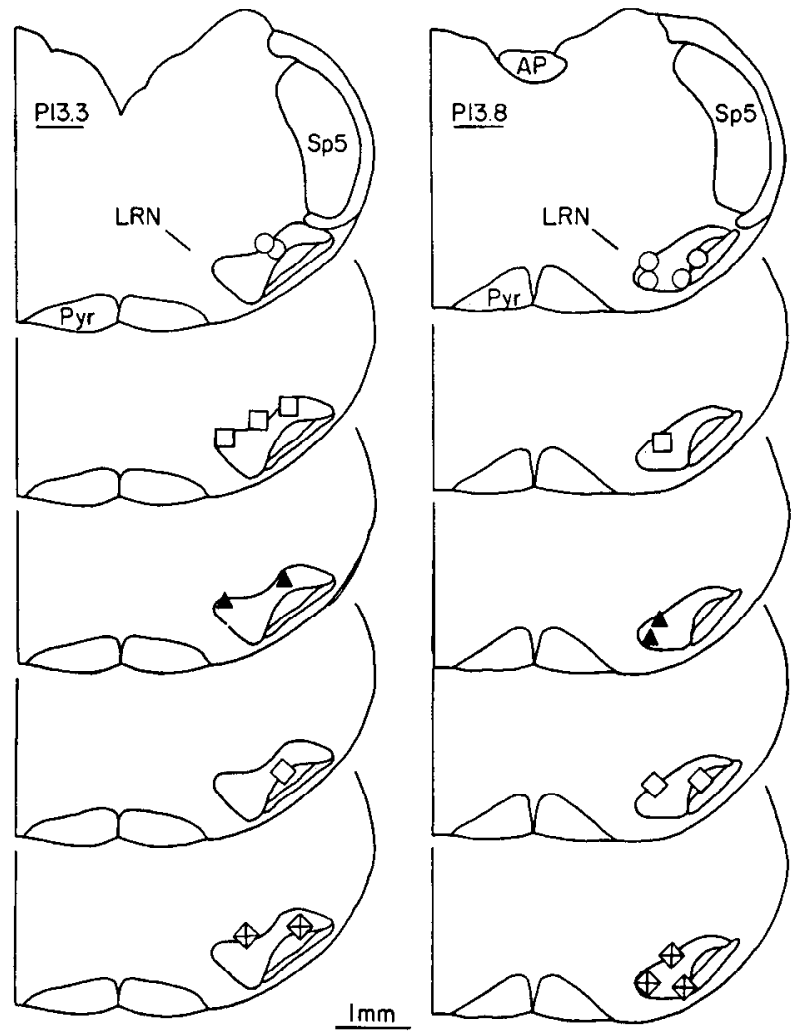

Baseline

- Yohimbine, $30 \mu \mathrm{g}$

Methysergide, $30 \mu \mathrm{g}$

- Prazosin, $30 \mu \mathrm{g}$

$\diamond$ Naloxone, $20 \mu \mathrm{g}$

- $\mathrm{H}_{2} \mathrm{O}$ Control, 400nl

Figure 5. Inhibition of responses to noxious thermal stimuli into conscious rats by microinjection of glutamate into the LRN. TF latency $(A)$ and HP latency $(B)$ are plotted against time following administration of $400 \mathrm{nl}$ of glutamate $(100 \mathrm{~mm})$ into the ventrolateral medulla at time 0 . Injection sites are illustrated in $C$. TF and HP latencies that precede time 0 represent the baseline latency (the average of 3 sequential trials prior to microinjection of glutamate). Inhibition of the TF reflex and hindpaw lick response by glutamate microinjected into the LRN in the absence (baseline) and in the presence of various pharmacological antagonists delivered intrathecally to the level of the lumbar enlargement indicates that only the selective $\alpha_{2}$-adrenoceptor antagonist yohimbine and the serotonergic antagonist methysergide attenuated the inhibitory effects of glutamate. Values are presented as means; standard errors are not indicated for reasons of clarity (see Table 2$)$. ${ }^{*}$ Significantly different $(p \leq 0.05)$ from corresponding baseline latency (repeated-measures ANOVA). Neither prazosin nor naloxone affected the significant antinociception in either the TF or HP tests produced by glutamate given at the sites indicated. $C$, Glutamate microinjection sites in the ventrolateral medulla of rats tested in the unanesthetized state in which yohimbine, methysergide, prazosin, or naloxone was administered intrathecally, or $400 \mathrm{nl}$ of water microinjected intracranially.

Control experiments in which yohimbine was injected to the level of the cervical spinal cord suggest that supraspinal $\alpha_{2}$ adrenoceptors do not contribute to the inhibition of the TF reflex produced by glutamate in the LRN.

Spinal serotonin receptors also appear to be involved in the descending inhibition produced by excitation of cell bodies in the LRN by glutamate, since methysergide antagonized this inhibition in both conscious and lightly anesthetized rats. Spinal serotonin receptors, which appear to be exclusively of the

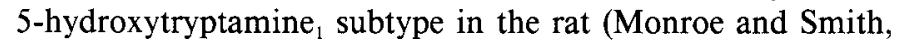

1983), have been implicated in numerous studies of inhibition of nociception (e.g., Belcher et al., 1978; Zemlan et al., 1983; Jensen and Yaksh, 1984). Gebhart and Ossipov (1986) reported that intrathecally administered methysergide attenuated the inhibition of the TF reflex produced by electrical stimulation in the LRN, although not as reliably as did yohimbine or phentolamine. The dose/volume studies presented here also suggest that intrathecally administered methysergide is not as potent as either phentolamine or yohimbine in antagonizing the inhibition of the TF reflex produced by glutamate in the LRN. There is evi- 
Table 2. Effect of receptor antagonist adminstered intrathecally on inhibition of the TF reflex and $H P$ responses by microinjection of glutamate into the LRN in conscious rats

\begin{tabular}{|c|c|c|c|c|c|c|c|}
\hline \multirow{2}{*}{\multicolumn{2}{|c|}{ Intrathecal treatment }} & \multicolumn{3}{|c|}{ Tail flick latency } & \multicolumn{3}{|c|}{ Hot plate latency } \\
\hline & & $n$ & Preglutamate & Postglutamate & $\bar{n}$ & Preglutamate & Postglutamate \\
\hline None (baseline) & & 9 & $2.6 \pm 0.2$ & $5.4 \pm 0.3$ & 8 & $9.8 \pm 1.0$ & $46.6 \pm 3.2$ \\
\hline Yohimbine & $30 \mu \mathrm{g}$ & 6 & $1.4 \pm 0.1^{\circ}$ & $2.0 \pm 0.3^{a}$ & 5 & $5.5 \perp 1.1^{a}$ & $22.0 \pm 3.2^{a}$ \\
\hline Prazosin & $30 \mu \mathrm{g}$ & 4 & $3.0 \pm 0.2$ & $6.2 \pm 0.4$ & 3 & $10.2 \pm 1.4$ & $48.7 \pm 5.9$ \\
\hline Methysergide & $30 \mu \mathrm{g}$ & 4 & $2.0 \pm 0.3^{a}$ & $2.6 \pm 0.3^{a}$ & 4 & $6.8 \pm 2.4$ & $12.9 \pm 4.3^{a}$ \\
\hline Naloxone & $20 \mu \mathrm{g}$ & 3 & $2.8 \pm 0.3$ & $5.5 \pm 0.1$ & 3 & $13.5 \pm 3.2$ & $55.9 \pm 4.1$ \\
\hline $\mathrm{H}_{2} \mathrm{O}$ control & $400 \mathrm{nl}$ & 5 & $2.5 \pm 0.2$ & $2.2 \pm 0.1^{a}$ & 4 & $11.6 \pm 2.9$ & $11.6 \pm 3.0^{a}$ \\
\hline
\end{tabular}

TF and HP latencies represent the means of 3 values recorded 2 min apart prior to microinjection of $400 \mathrm{nl}$ of glutamate (preglutamate), or 2 values recorded within 3 min following microinjection of glutamate into the LRN (postglutamate) Glutamate injection sites are illustrated in Figure $4 B$. Baseline valucs indicate TF and $H P$ latencics in the absence of any intrathecal treatment. All antagonists were administered in the subarachnoid space to the level of the lumbar enlargement (catheter, $7.5 \mathrm{~cm}$ ). The $\mathrm{H}_{2} \mathrm{O}$ control group represents a group in which $400 \mathrm{nl}$ of distilled water was microinjected into the ventrolateral medulla into sites where glutamate had previously produced elevation of TF and HP latencies (see text and Fig. 4B).

a Significantly different $(p \leq 0.05)$ from corresponding baseline response latency (2-way ANOVA and Tukey's studentized range test for post hoc comparison).

dence that serotonergic and catecholaminergic systems interact at the level of the spinal cord (Hammond and Yaksh, 1984). This might explain why yohimbine completely blocked the effects of glutamate in the LRN, yet methysergide also attenuated the effect of glutamate.

Opioid receptors in the spinal cord do not mediate inhibition produced by selective excitation of cell bodies in the LRN. Twice the dose of naloxone that has been reported to attenuate inhibition of the TF reflex produced by glutamate microinjected into the ventromedial medulla (Jensen and Yaksh, 1984) had no significant effect on inhibition of the TF reflex or HP response produced by glutamate microinjected into the LRN.

In the aggregate, these studies indicate that the spinal receptors involved in inhibition of responscs to noxious thermal stimuli produced by selective activation of cell bodies in the LRN by microinjection of glutamate are similar to those mediating inhibition produced by focal electrical stimulation in the LRN (Gebhart and Ossipov, 1986). The similarities in glutamate- and stimulation-produced inhibition of nociceptive responses from the LRN do not rule out the possibility that activation of neuronal fibers, as well as of somata, in the ventrolateral medulla may contribute to inhibition of the TF reflex produced by focal electrical stimulation in the LRN (for example, orthodromic activation of bulbospinal descending inhibitory fibers or antidromic activation of ascending fibers, which activate descending inhibitory systems; see, e.g., Jensen and Yaksh, 1984, and the introduction). The spinal receptors implicated in the inhibition of the TF reflex and in HP responses produced by microinjection of glutamate into the ventromedial medulla or periaqueductal gray (Satoh et al., 1983; Jensen and Yaksh, 1984) are not identical to those that mediate descending inhibition from the LRN. This supports the argument that descending inhibition from the LRN is unique and not the result of diffusion of glutamate to other inhibitory systems originating more rostrally in the brain stem.

A problem inherent in the use of behavioral or reflex responses to charactcrize descending inhibitory systems is whether elevation of response latencies, termed antinociception, represents the modulation of sensory processes or of motor functions. The inhibition of reflexes and responses to noxious thermal stimuli initiated by activation of cell bodies in the LRN may be the result of neuronal interactions that affect rostrad transmission of nociceptive information, efferent transmission from motoneurons in the ventral horn of the spinal cord, or a combination of both mechanisms (see Discussions in Jensen and Yaksh, 1984, and Ossipov and Gebhart, 1986). The heat-evoked nociceptive TF reflex and the more complex, supraspinally integrated hindpaw lick response in the HP test were clearly inhibited by glutamate microinjected into the LRN. Agitated behavior (e.g., stomping and jumping) of rats in the HP test indicated that the $55^{\circ}$ heat stimulus was noxious despite the fact that the hindpaw lick was clearly blocked following microinjection of glutamate into the LRN. This observation, and the transient rigidity produced by glutamate when microinjected into the ventrolateral medulla, suggests that activation of cell bodies in or near the LRN does affect motor function, and that inhibition of the pawlick response from the I RN may not represent a reduction in sensory transmission. However, that intrathecally administered monoamine receptor antagonists alter the effects of glutamate in the HP test suggests that the effects on supraspinally organized behavior involve spinal circuitry, likely of a sensory nature. This is supported by electrical stimulation-produced inhibition of the responses of spinal dorsal horn neurons to electrical activation of $\mathrm{C}$ fibers in the cat (Morton et al., 1983). In the rat, both focal electrical stimulation and glutamate in the LRN reliably inhibit spinothalamic dorsal horn neuronal responses to a noxious heat stimulus (A. J. Janss and G. F. Gebhart, unpublished observations). This suggests that descending inhibition from the LRN does indeed involve sensory processing. The extensive connectivity of the LRN with central pathways regulating motor and sensorimotor function (see the introduction) would be consistent with these results.

The ventrolateral medulla is also involved in the maintenance and regulation of cardiovascular tone. Electrical stimulation in the caudal ventrolateral medulla near the LRN can produce both pressor and depressor responses (Imaizumi et al., 1985; see references in Janss et al., 1987a). We have recently demonstrated that the pressor effects produced by electrical stimulation in and near the LRN are independent of the inhibition of the TF reflex produced by electrical stimulation (Janss et al., 1987 a). In the present study, glutamate microinjected into the LRN resulted in a depressor response that exhibited dependence 
on the dose/volume, confirming previous reports (Imaizumi et al., 1985; Janss et al., 1987a). The decrease in blood pressure did not correlate with the inhibition of the TF reflex produced by glutamate. This complements our previous report in that it provides statistical evidence that the depressor effects mediated by the caudal ventrolateral medulla are also independent of descending inhibition from the LRN.

As yet unresolved is the question of the origin of descending adrenergic and serotonergic inhibitory systems that are activated by glutamate or electrical stimulation in the LRN. Although adrenaline-containing (C1) and noradrenaline containing (A1) cell groups are located near the LRN (Dahlström and Fuxe, 1965; Kalia et al., 1985a-c), there is controversy as to whether noradrenergic projections from the A1 cell group descend to the spinal cord. Numerous studies suggest that they do not (e.g., Westlund et al., 1983; see references and Discussion in Janss et al., 1987a, b); however, IIudson et al. (1986) have reported that noradrenaline-containing neurons from the A1 cell group do project to the spinal cord. Adrenaline-containing fibers from the C1 cell group have been reported to terminate in the thoracic spinal cord (Ross et al., 1984), but projections to the lumbar spinal cord have yet to be demonstrated. Serotonin-containing cell bodies in the medulla with projections to the spinal cord (cell groups B1, 2, and 3) reside medial and rostral to the LRN (Dahlström and Fuxe, 1965; Bowker et al., 1981; Björklund and Skagerberg, 1982). The apparent conflict between physiological data indicating that activation of cell bodies in the LRN produces inhibition of responses to noxious stimuli mediated by spinal catecholaminergic or serotonergic terminals and the failure to demonstrate spinopetal noradrenergic or serotonergic projections from the LRN may be explained if (1) current anatomical techniques are not sufficiently sensitive to resolve existing monoaminergic connections between the LRN or Al cell group to the spinal cord, or (2) descending inhibition from the LRN is polysynaptic, with neurons in the LRN projecting rostrally to, and activating, a secondary monoaminergic neuron that descends to the lumbar spinal cord. The principal sources of noradrenergic and serotonergic innervation of the spinal cord in the rat are believed to be the nucleus locus coeruleus/subcoeruleus (Nygren and Olson, 1977; Björklund and Skagerberg, 1982; Westlund et al., 1983) and the nucleus raphe magnus (Bowker et al., 1981; Björklund and Skagerberg, 1982), respectively. Efferent fibers from the LRN to the locus coeruleus (Loewy et al., 1981; Marchand and Hagino, 1983) and the nucleus raphe magnus (Qvist et al., 1983) have been demonstrated. It is not known, however, if these projections are relevant to the descending inhibition produced by activation of cell bodies in the LRN. Preliminary results suggest, however, that descending inhibition from the LRN does not rely on a rostral loop to the locus coeruleus (A. J. Janss and G. F. Gebhart, unpublished observations).

To summarize, selective activation of cell bodies in or near the LRN by microinjection of glutamate results in the inhibition of reflexes and responses to noxious thermal stimuli, which is mediated at least in part by spinal $\alpha_{2}$-adrenoceptors and serotonin rcceptors. This inhibition demonstrates dependence on the dose/volume of glutamate administered and is evident in conscious rats, as well as in rats lightly anesthetized with pentobarbital. These results confirm and extend previous reports establishing the role of the LRN in antinociception (Hall et al., 1982; Morton et al., 1983; Gebhart and Ossipov, 1986; Ossipov and Gebhart, 1986; Janss et al., 1987a, b), and further illustrate the disparity between anatomic and physiologic-pharmacologic results regarding spinopetal noradrenergic projections from the caudal ventrolateral medulla. The extent to which this inhibition from the LRN reflects a modulation of spinal nociceptive transmission or of spinal motor outflow has not been determined, nor has the supraspinal origin of the spinal monoaminergic terminals mediating this inhibition.

\section{References}

Aimone, L. D., and G. F. Gebhart (1986) Stimulation-produced spinal inhibition from the midbrain in the rat is mediated by an excitatory amino acid neurotransmitter in the medial medulla. J. Neurosci. 6 : 1803-1813.

Limone, L. D., and G. F. Gebhart (1987) Spinal monoamine mediation of stimulation-produced antinociception from the lateral hypothalamus. Brain Res. 403: 290-300.

Behbehani, M. M., and H. L. Fields (1979) Evidence that an excitatory connection between the periaqueductal gray and nucleus raphe magnus mediates stimulation produced analgesia. Brain Res. 170: 85-93.

Belcher, G., R. W. Ryall, and R. Schaffner (1978) The differential effects of 5-hydroxytryptamine, noradrenalin and raphe stimulation on nociceptive and non-nociceptive dorsal horn interneurons in the cat. Brain Res. 151: 307-321.

Björklund, A., and G. Skagerberg (1982) Descending monoaminergic projections to the spinal cord. In Brain Stem Control of Spinal Cord Mechanisms, B. Sjölund and A. Björklund, eds., pp. 55-88, Elsevier, Amsterdam.

Bowker, R. M., K. N. Westlund, and J. D. Coulter (1981) Origins of serotonergic projections to the spinal cord in rat: An immunocytochemical-retrograde transport study. Brain Res. 226: 187-199.

Brodal, P., J. Marśala, and A. Brodal (1967) The cerebral cortical projection to the lateral reticular nucleus in the cat, with special reference to the sensorymotor cortical areas. Brain Res. 6: 252-274.

Carstens, E. (1982) Inhibition of spinal dorsal horn neuronal responses to noxious skin heating by medial hypothalamic stimulation in the cat. J. Neurophysiol. 41: 808-822.

Carstens, E. (1986) Hypothalamic inhibition of rat dorsal horn neuronal responses to noxious skin heating. Pain 25: 95-107.

Carstens, E., M. Fraunhoffer, and S. N. Suberg (1983) Inhibition of spinal dorsal horn neuronal responses to noxious skin heating by lateral hypothalamic stimulation in the cat. J. Neurophysiol. 50: 192204.

Corraja, N., I. Grofavá, O. Pompeiano, and F. Walberg (1977) The lateral reticular nucleus in the cat. I. An experimental anatomical study of its spinal and supraspinal afferent connections. Neuroscience 2: $537-553$.

Coulter, J. D., R. A. Maunz, and W. D. Willis (1974) Effect of stimulation of sensory motor cortex on primate spinothalamic tract cells. Brain Res. 65: 351-356.

Cunningham, P. M., G. E. Goldsmith, and R. F. Hellon (1986) Medial hypothalamic stimulation produces analgesia to facial heating in unrestrained rats. Neurosci. Lett. 68: 107-111.

Dahlström, A., and K. Fuxe (1965) Evidence for the existence of monoamine neurons in the central nervous system. II. Experimentally induced changes in intraneuronal amine levels of bulbo-spinal neuron systems. Acta Physiol. Scand. 64: 1-36.

Deitrichs, E. (1983) Cerebellar nuclear afferents from the lateral reticular nucleus in the cat. Brain Res. 288: 320-324.

Deitrichs, E., and F. Walberg (1979) The cerebellar projection from the lateral reticular nucleus as studied with retrograde transport of horseradish peroxidase. Anat. Embryol. 155: 243-290.

Fitzgerald, M. (1982) The contralateral input to the dorsal horn of the spinal cord in the decerebrate rat. Brain Res. 236: 275-287.

Fries, W., and W. Zieglgänsberger (1974) A method to discriminate axonal from cell body activity and to analyze "silent cells." Exp. Brain Res. 21: 441-445.

Gebhart, G. F. (1986) Modulatory effects of descending systems on spinal dorsal horn neurons. In Spinal Afferent Processing, T. L. Yaksh, ed., pp. 391-416, Plenum, New York.

Gebhart, G. F., and M. Ossipov (1986) Characterization of inhibition of the spinal nociceptive tail-flick reflex in the rat from the medullary lateral reticular nucleus. J. Neurosci. 6: 701-713. 
Gebhart, G. F., J. Sandkühler, J. G. Thalhammer, and M. Zimmermann (1983a) Quantitative comparison of inhibition of spinal cord nociceptive information by stimulation in the periaqueductal gray or nucleus raphe magnus of the cat. J. Neurophysiol. 50: 1433-1445.

Gebhart, G. F., J. Sandkühler, J. G. Thalhammer, and M. Zimmermann (1983b) Inhibition of spinal nociceptive information by stimulation in midbrain of the cat is blocked by lidocaine microinjected in nucleus raphe magnus and medullary reticular formation. J. Neurophysiol. 50: 1446-1459.

Gerhart, K. D., R. P. Yezierski, Z. R. Fang, and W. D. Willis (1983) Inhibition of primate spinothalamic tract neurons by stimulation in ventral posterior lateral (VPL) thalamic nucleus: Possible mechanisms. J. Neurophysiol. 49: 406-423.

Goodchild, A. K., R. A. L. Dampney, and R. Bandler (1982) A method for evoking physiologic responses by stimulation of cell bodies, but not axons of passage, within localized regions of the central nervous system. J. Neurosci. Methods 6: 351-363.

Hall, J. G., A. W. Duggan, C. P. Morton, and S. M. Johnson (1982) The localization of brainstem neurons tonically inhibiting dorsal horn neurons of the cat. Brain Res. 244: 215-222.

Hammond, D. L., and T. L. Yaksh (1984) Antagonism of stimulationproduced antinociception by intrathecal administration of methysergide or phentolamine. Brain Res. 298: 329-337.

Hrycyshyn, A. W., and B. A. Flümerfelt (1981) A light microscopic investigation of the afferent connections of the lateral reticular nucleus in the cat. J. Comp. Neurol. 197: 447-502.

Hudson, M. E., K. Fuxe, M. Goldstein, and M. Kalia (1986) Spinal projections of noradrenergic and adrenergic neurons in the medulla oblongata: New evidence in central cardiovascular control. Soc. Neurosci. Abstr. 12: 535.

Imaizumi, T., A. R. Granata, E. E. Benarroch, A. F. Sved, and D. J. Reis (1985) Contributions of arginine vasopressin and the sympathetic nervous system to fulminating hypertension after destruction of neurons of the caudal ventrolatcral medulla in the rat. J. Hypertension 3: 491-501.

Janss, A. J., and G. F. Gebhart (1986) Antinociception produced by activation of cell bodies in the lateral reticular nucleus (LRN). Neurosci. Abstr. 12: 1015.

Janss, A. J., B. F. Cox, M. J. Brody, and G. F. Gebhart (1987a) Dissociation of antinociceptive from cardiovascular effects of stimulation in the lateral reticular nucleus in the rat. Brain. Res. 405: 140-149.

Janss, A. J., S. L. Jones, and G. F. Gebhart (1987b) Effect of spinal norepinephrine depletion on descending inhibition of the tail flick reflex from the locus coeruleus and lateral reticular nucleus in the rat. Brain Res. 400: 40-52.

Jensen, T. S., and T. L. Yaksh (1984) Spinal monoamine systems partly mediate the antinociceptive effects produced by glutamate at brainstem sites. Brain Res. 321: 287-297.

Jones, B. E., and T. Yang (1985) The efferent projections from the reticular formation and the locus coeruleus studied by anterograde and retrograde axonal transport in the rat. J. Comp. Neurol. 242: 5692.

Jones, S. L., and G. F. Gebhart (1986a) Characterization of coeruleospinal inhibition of the nociceptive tail flick reflex in the rat: Mediation by spinal $\alpha-2$ adrenoceptors. Brain Res. 364: 315-320.

Jones, S. L., and G. F. Gebhart (1986b) Quantitative characterization of coeruleospinal inhibition of nociceptive transmission in the rat. J. Neurophysiol. 56: 1397-1410.

Kalia, M., K. Fuxe, and M. Goldstein (1985a) Rat medulla oblongata. I. Cytoarchitectonic considerations. J. Comp. Neurol. 233: 285-307.

Kalia, M., K. Fuxe, and M. Goldstein (1985b) Rat medulla oblongata. II. Dopaminergic, noradrenergic $\left(\Lambda_{1}\right.$ and $\left.\Lambda_{2}\right)$ and adrenergic neurons, nerve fibers, and presumptive terminal processes. J. Comp. Neurol. 233: 308-322.

Kalid, M., K. Fuxe, and M. Goldstein (1985c) Rat medulla oblongata. III. Adrenergic $\left(C_{1}\right.$ and $\left.C_{2}\right)$ neurons, nerve fibers and presumptive terminal processes. J. Comp. Neurol. 233: 333-349.

Künzle, H. (1973) The topographical organization of spinal afferents to the lateral reticular nucleus of the cat. J. Comp. Neurol. 149: 103106.

Künzle, H., and M. Wiesendanger (1974) Pyramidal connections to the lateral reticular nucleus in the cat: A degeneration study. Acta Anat. 88: 105-114.
Loewy, A. D., J. H. Wallach, and S. McKellar (1981) Efferent connections of the ventral medulla oblongata in the rat. Brain Res. Rev. 3: 63-80.

Marchand, J. E., and N. Hagino (1983) Afferents to the periaqueductal gray in the rat: A horseradish peroxidase study. Neuroscience 9: 95106.

Menétrey, D., J. dePommery, and J. M. Besson (1984) Electrophysiological characteristics of lumbar spinal cord neurons backfired from the lateral reticular nucleus in the rat. J. Neurophysiol. 82: 595-611.

Menétrey, D., G. J. Giesler, Jr., and J. M. Besson (1977) An analysis of response properties of spinal cord dorsal horn neurons to nonnoxious and noxious stimuli in the spinal rat. Exp. Brain Res. 27: 15-33.

Menétrey, D., F. Roudier, and J. M. Besson (1983) Spinal neurons reaching the lateral reticular nucleus as studied in the rat by retrograde transport of horseradish peroxidase. J. Comp. Neurol. 220:439-452.

Monroe, P. J., and D. J. Smith (1983) Characterization of multiple $\left[\mathrm{H}^{3}\right] 5$-hydroxytryptamine binding sites in rat spinal cord tissue. $\mathrm{J}$. Neurosci. 3: 349-355.

Morton, C. R., S. M. Johnson, and A. W. Duggan (1983) Lateral reticular regions and the descending control of dorsal horn neurons of the cat: Selective inhibition by electrical stimulation. Brain Res. 275: 13-21.

Ness, T. J., and G. F. Gebhart (1986) Centrifugal modulation of the rat tail flick reflex evoked by graded noxious heating of the tail. Brain Res. 386: 41-52.

Nygren, L., and L. Olson (1977) A new major projection from locus coeruleus: The main source of noradrenergic nerve terminals in the ventral and dorsal columns of the spinal cord. Brain Res. 132: 8593.

Ossipov, M., and G. F. Gebhart (1986) Opioid, cholinergic and alphaadrenergic influences on the modulation of nociception from the lateral reticular nucleus of the rat. Brain Res. 384: 282-293.

Paxinos, G., and C. Watson (1982) The Rat Brain in Stereotaxic Coordinates, Academic, New York.

Qvist, H., E. Deitrichs, L. S. Röste, and F. Walberg (1983) A projection from the raphe nuclei to the lateral reticular nucleus in the cat. Arch. Ital. Biol. 121: 249-257.

Qvist, H., E. Deitrichs, and F. Walberg (1984) An ipsilateral projection from the red nucleus to the lateral reticular nucleus in the cat. Anat. Embryol. 170: 327-330.

Reynolds, D. V. (1969) Surgery in the rat during electrical analgesia induced by focal brain stimulation. Science 164: 444-445.

Rose, J. D. (1981) Projections to the caudalateral medulla from the pons, midbrain and diencephalon in the cat. Exp. Neurol. 72: 413428.

Ross, C. A., D. A. Ruggiero, T. H. Joh, D. A. Park, and D. J. Reis (1984) Rostral ventrolateral medulla selective projections to the thoracic autonomic cell column from the region containing $\mathrm{C}_{1}$ adrenaline neurons. J. Comp. Neurol. 228: 168-185.

Röste, L. D., E. Deitrichs, and F. Walberg (1985) A projection from the periaqueductal gray to the lateral reticular nucleus in the cat. Anat. Embryol. 170: 339-343.

Sandkühler, J., and G. F. Gebhart (1984) Characterization of inhibition of a spinal nociceptive reflex by stimulation medially and laterally in the midbrain and medulla in the pentobarbital-anesthetized rat. Brain Res. 305: 67-76.

Satoh, M., R. Oku, and A. Akaike (1983) Analgesia produced by microinjection of L-glutamate into the rostral ventromedial bulbar nuclei of the rat and its inhibition by intrathecal $\alpha$-adrenergic blocking agents. Brain Res. 261: 361-364.

Shokunbi, M. T., A. W. Hrycyshyn, and B. A. Flümerfelt (1986) A horseradish peroxidase study of the cerebral and cortical afferents to the lateral reticular nucleus in the rat. J. Comp. Neurol. 248: 441454.

Sotgiu, M. L. (1986) Inhibition of the nociceptive jaw opening reflex by lateral reticular nucleus (LRN) in the rabbit. Neurosci. Lett. 65 : $145-148$.

Starke, K. (1981) $\alpha$-Adrenoceptor subclassification. Rev. Physiol. Biochem. Pharmacol. 88: 199-236.

Watkins, L. R., and D. J. Mayer (1982) Organization of endogenous opiate and nonopiate pain control systems. Science 216: 1185-1192.

Westlund, K. N., and J. D. Coulter (1980) Descending projections of 
the locus coeruleus and subcoeruleus/medial parabrachial nuclei in monkey: Axonal transport studies and dopamine- $\beta$-hydroxylase immunocytochemistry. Brain Res. Rev. 2: 235-264.

Westlund, K. N., R. M. Bowker, M. G. Ziegler, and J. D. Coulter (1983) Noradrenergic projections to the spinal cord of the rat. Brain Res. 263: 15-31.

Yaksh, T. L., and T. A. Rudy (1976) Chronic catheterization of the spinal subarachnoid spaces. Physiol. Behav. 17: 1031-1036.

Yaksh, T. L., and T. A. Rudy (1978) Narcotic analgesics: CNS sites and mechanisms of action as revealed by intracerebral injection techniques. Pain 4: 299-359.
Yezierski, R. P., K. D. Gerhart, B. J. Schrock, and W. D. Willis (1983) A further examination of cortical stimulation on primate spinothalamic tract cells. J. Neurophysiol. 49: 424-441.

Zemlan, F. P., L. Kow, and D. W. Pfaff (1983) Spinal serotonin (5HT) receptor subtypes and nociception. J. Pharmacol. Exp. Ther. 226: 477-485.

Zorman, G., I. D. Hentall, J. E. Adams, and H. L. Fields (1981) Naloxone-reversible analgesia produced by microstimulation in the rat medulla. Brain Res. 219: 137-148. 